\title{
Crystallization Temperature Effect on Tungsten Oxide Thin Films Prepared by Sol-Gel Method for Ultraviolet-Visible Photodetectors
}

\author{
Pei-Hsing Huang, Nai-Jen Cheng, ${ }^{1}$ Shang-Chao Hung,,$^{2 *}$ and Chia-Yi Lin ${ }^{3}$ \\ Department of Mechanical Engineering, National Pingtung University of Science and Technology, \\ Pingtung 912, Taiwan \\ ${ }^{1}$ Institute of Photonics and Communications, National Kaohsiung University of Applied Sciences, \\ Kaohsiung 80778, Taiwan \\ ${ }^{2}$ Department of Information Technology \& Communication, Shih Chien University, Kaohsiung Campus, \\ Neimen, Kaohsiung 845, Taiwan \\ ${ }^{3}$ Graduate Institute of Electro-Optical Engineering \& Department of Electronic Engineering, \\ National Taiwan University of Science and Technology, Taipei 106, Taiwan
}

(Received August 31, 2015; accepted January 6, 2016)

Keywords: tungsten oxide, photodetectors, responsivity, $\mathrm{W}_{18} \mathrm{O}_{49}$

Thin films of tungsten oxide with different crystallization temperatures were synthesized by the sol-gel method and used to fabricate photodetectors. The surface morphology, microstructure, and crystal structure of the films were analyzed by scanning electron microscopy, X-ray diffraction spectroscopy, and photoluminescence spectroscopy, respectively. The effects of annealing temperature and grain size of a grain on the structure and optoelectrical properties were examined. The responsivity at $410 \mathrm{~nm}$ and the rejection ratio for the $600{ }^{\circ} \mathrm{C}$-annealed $\mathrm{W}_{18} \mathrm{O}_{49}$ film were 0.0268 $\mathrm{A} / \mathrm{W}$ and 407.8, respectively. Meanwhile, the relationships among thin films were also investigated and discussed. A photo-to-dark current contrast ratio of $6.5 \times 10^{2}$ was achieved. $I-V$ measurement also indicated that the optimum annealing temperature for the substrates was $600^{\circ} \mathrm{C}$.

\section{Introduction}

Photodetectors (PDs) are important devices that can be used in free-space communication, guidance, ozone-layer monitoring, and thermal imaging systems. Metal oxides are attractive not only for scientific interest but also for potential applications in electronic and photonic devices. Therefore, semiconductor PDs based on metal oxides have been proven to be excellent in terms of essential characteristics such as sensitivity, long-term stability, robustness, and price. ${ }^{(1,2)}$

Tungsten oxide, owing to its mixed oxidation states, is the most widely studied electrochromic material. This material, which has been studied extensively both in the form of thin films and nanostructures, has applications in smart windows, rear-view mirrors in automobiles, and gas sensors because of its electrochromism, gasochromism, and photochromism. However, to the best of our knowledge, PDs based on tungsten oxide films are still very rare.

Recently, tungsten oxide films have been prepared by a variety of methods, including vacuum evaporation, ${ }^{(3)}$ anodic oxidation, ${ }^{(4)}$ spray pyrolysis, ${ }^{(5)}$ sol-gel synthesis, ${ }^{(6,7)}$ sputtering, ${ }^{(8)}$ and laser "Corresponding author: e-mail: schung99@gmail.com 
ablation. ${ }^{(9)}$ Among a variety of available film deposition techniques, the sol-gel technique is the most promising method of preparing large films, ${ }^{(10,11)}$ and it has many advantages such as the need for simple equipment and low cost. The films obtained by this method are also more uniform than those obtained by other methods. Moreover, photoconduction of metal oxide is governed by the desorption and adsorption of oxygen.(12-14) Owing to high optical sensitivity, gas sensitivity, and stability properties, tungsten oxide synthesized by the sol-gel method will be a promising candidate for fabricating gas-dependent PD. ${ }^{(15)}$ Therefore, the relationships among crystallization temperature, effect of crystal size on tungsten oxide thin films, and corresponding optical and electrical characteristics of the thin films prepared by sol-gel method should be further studied.

In this work, thin films of tungsten oxide with different crystallization temperatures were synthesized by the sol-gel method and were designed to fabricate PDs. The optical and electrical characteristics of the thin films were studied accordingly; meanwhile, the relationships among the thin films were also investigated and discussed.

\section{Materials and Methods}

Firstly, tungsten oxide thin films were deposited on a quartz template by the sol-gel method. To prepare the precursor powder of tungsten oxides, tungsten powder (99.9\%) was added to 50 $\mathrm{mL}$ of $\mathrm{H}_{2} \mathrm{O}_{2}(30 \%)$. After the tungsten powder was entirely dissolved, acetic acid was added to the solution. After the reaction was completed, the mixture solution was evaporated to remove organic residuals and the precursor powder of the tungsten oxides was produced. After that, the precursor powder was mixed with isopropyl alcohol (IPA) (weight ratio of powder: IPA $=1: 3$ ) and $4 \mathrm{wt} \%$ citric acid was added to the solution, and then a tungsten oxide gel was prepared. Next, a quartz template was cleaned with acetone, isopropyl alcohol, and distilled water. After gel solution coating, the substrate was sectioned into 20 small pieces for five groups, followed by thermal treatment for $1 \mathrm{~h}$ in $\mathrm{O}_{2}$ atmosphere at five different crystallization temperatures: 500, 550, 600, 650, and $700{ }^{\circ} \mathrm{C}$.

Secondly, the surface morphology and microstructure of the samples were characterized by fieldemission scanning electron microscopy (FESEM). X-ray diffraction (XRD) pattern was used to examine the chemical composition. Optical properties were then inspected by photoluminescence (PL) measurement.

Thirdly, ultraviolet-visible (UV) PDs were fabricated and based on metal-semiconductor-metal (MSM) structures. A gold ( $\mathrm{Au}$ ) film of $40 \mathrm{~nm}$ thickness was patterned onto the sample surface by electron beam evaporation to serve as the metal contacts. During the Au evaporation process, the base pressure was kept at $5 \times 10^{-5}$ Torr. The active region of the PD was 1950 (length) $\times 4000$ (width) $\mu \mathrm{m}^{2}$, and the space between the contact electrodes was $150 \mu \mathrm{m}$.

Fourthly, an Agilent B1500A semiconductor device analyzer was employed to measure the current-voltage characteristics both in the dark and under illumination. The experimental setup contained a $250 \mathrm{~W}$ xenon white-light source through a monochrometer. The monochromatic light was separated in two parts: one was projected onto the samples and the other was connected to a power meter. The output power of the monochromatic light could be measured using the power meter. From the probe stations, two probes were linked to the Agilent B1500A semiconductor device analyzer, which could be controlled by a computer. Finally, the spectral responsivity of the PDs was measured using a Jobin Yvon-Spex system with a $300 \mathrm{~W}$ xenon arc lamp light source. 


\section{Results}

\subsection{Analyses of surface morphology and structural characteristics}

Figure 1(a) shows top-view FESEM images of the $\mathrm{W}_{18} \mathrm{O}_{49}$ film, which was synthesized by the sol-gel method without heat treatment. Figures 1(b)-1(f) show top-view FESEM images of the $\mathrm{W}_{18} \mathrm{O}_{49}$ films, which were synthesized by the sol-gel method with postannealing treatment for $1 \mathrm{~h}$ in $\mathrm{O}_{2}$ atmosphere at $500,550,600,650$, and $700{ }^{\circ} \mathrm{C}$, respectively. The insets in Fig. 1 show crosssectional FESEM images of the $\mathrm{W}_{18} \mathrm{O}_{49}$ films without and with heat treatment. It was found that the thickness of the precursor film without heat treatment was $1.43 \mu \mathrm{m}$. Also, the thickness of the $\mathrm{W}_{18} \mathrm{O}_{49}$ film was gradually decreased to $0.86 \mu \mathrm{m}$ as the annealing temperature was increased to 700 ${ }^{\circ} \mathrm{C}$. This result suggests that the thickness of the $\mathrm{W}_{18} \mathrm{O}_{49}$ films decreased with increasing annealing temperature. These images imply the large $\mathrm{W}_{18} \mathrm{O}_{49}$ migration rate on the substrate surface and the enhanced nucleation between tungsten and oxide at high temperatures.

Figure 2 shows XRD spectra measured from the as-deposited $\mathrm{W}_{18} \mathrm{O}_{49}$ thin film and from those with various crystallization temperatures $\left(500,550,600,650\right.$, and $\left.700{ }^{\circ} \mathrm{C}\right)$. For the substrates with various crystallization temperatures $\left(500,550,600,650\right.$, and $\left.700{ }^{\circ} \mathrm{C}\right)$, one strong XRD peak at $2 \theta$ $=23.54^{\circ}$ and two weak XRD peaks at $24.52^{\circ}$ and $48.20^{\circ}$ were observed, which were referred to as having the orientations of $(010),(-111)$, and $(020)$, respectively. The lattice constants of the monoclinic phase $\mathrm{W}_{18} \mathrm{O}_{49}$ crystal are $\beta=115.2^{\circ}, a=18.28 \AA, b=3.775 \AA$, and $c=13.98 \AA$ (JCPDS card no. 05-0392). It was also found that all the $\mathrm{W}_{18} \mathrm{O}_{49}$ thin films showed sharp diffraction peaks with the highest intensity at $2 \theta=23.05^{\circ}$. Furthermore, as we increased the annealing temperature, the $\mathrm{W}_{18} \mathrm{O}_{49}(010)$ peak increased rapidly while the (300) peak totally disappeared. As we increased the annealing temperature to $600{ }^{\circ} \mathrm{C}$, the $\mathrm{W}_{18} \mathrm{O}_{49}(010)$ XRD peak became extremely sharp and strong. These phenomena should be attributed to the enhanced thermal energy of crystallization
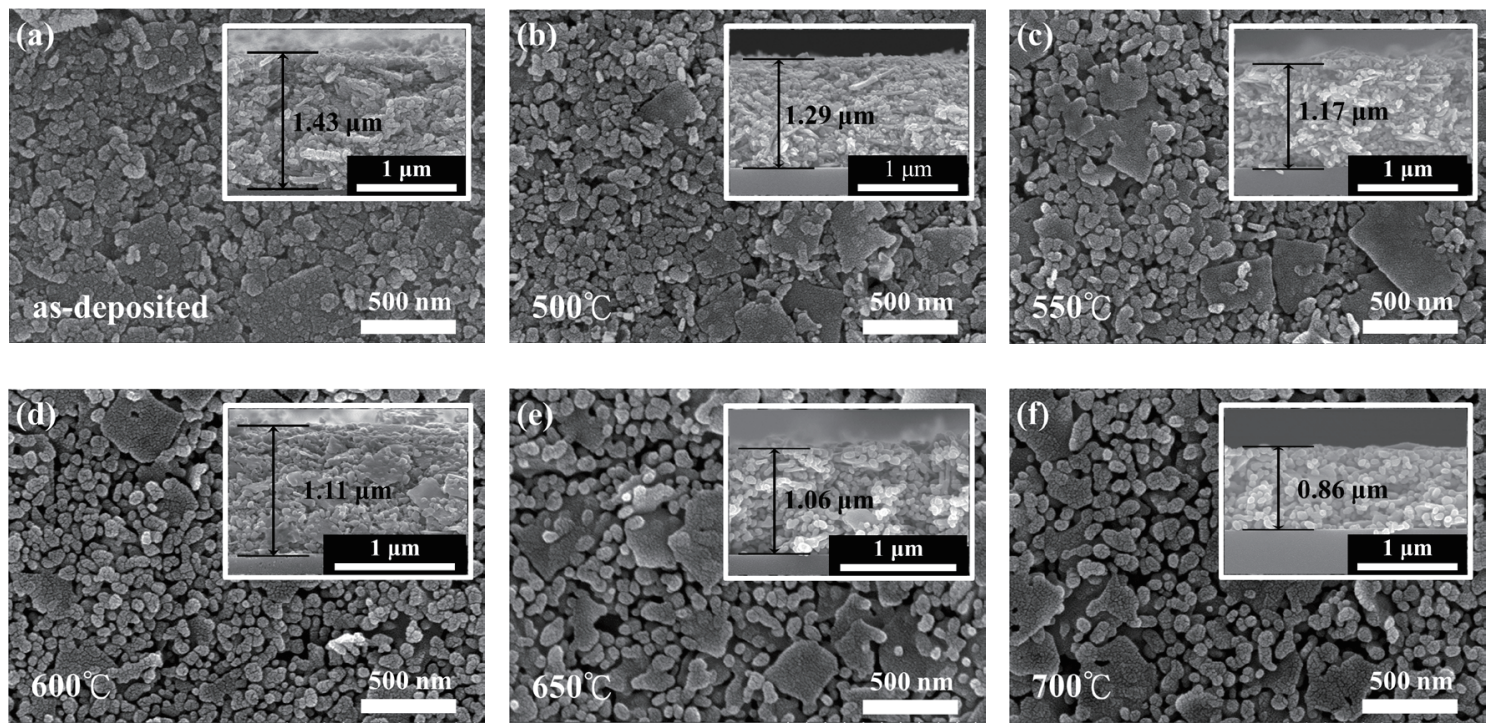

Fig. 1. Top-view FESEM images of $\mathrm{W}_{18} \mathrm{O}_{49}$ thin films (a) as-deposited and one-hour-annealed at (b) 500, (c) 550, (d) 600 , (e) 650 , and (f) $700{ }^{\circ} \mathrm{C}$. Insets show the corresponding cross-sectional FESEM images. 


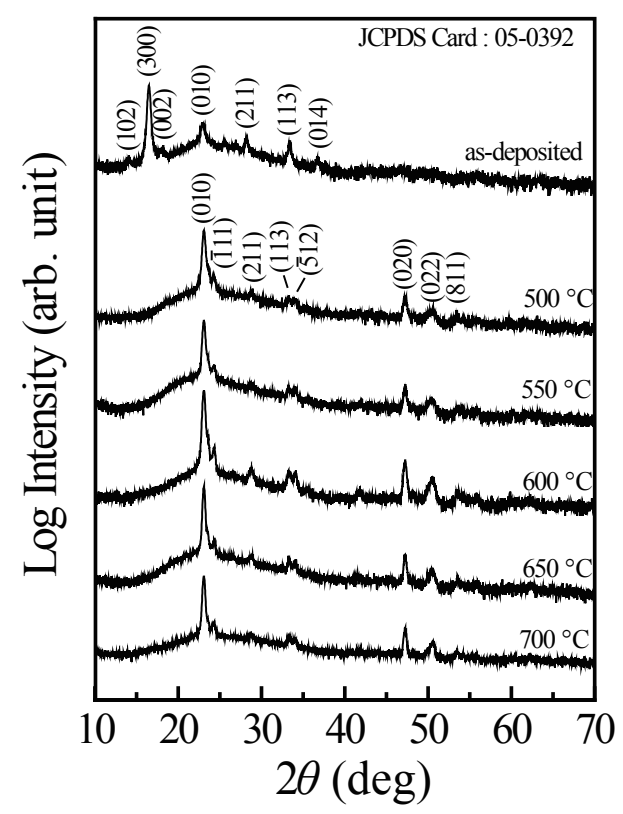

Fig. 2. XRD spectra of $\mathrm{W}_{18} \mathrm{O}_{49}$ thin films with different crystallization temperatures.

as we increased the annealing temperature. As we know, a higher annealing temperature could provide more thermal energy to the $\mathrm{W}_{18} \mathrm{O}_{49}$ film for crystallization and the crystal quality was then improved. ${ }^{(16)}$

As we further increased the annealing temperature from 600 to $700{ }^{\circ} \mathrm{C}$, it can be seen that the intensity of the $\mathrm{W}_{18} \mathrm{O}_{49}(010) \mathrm{XRD}$ peak located at $2 \theta=23.54^{\circ}$ decreased significantly. Other than the $\mathrm{W}_{18} \mathrm{O}_{49}(010)$ XRD peak, we observed that the other two weak XRD peaks also decreased as we further increased the annealing temperature to $700{ }^{\circ} \mathrm{C}$. This should be attributed to the oversupply of thermal energy. We consider that variations in the grain boundary energy made some of the grains grow in an unusual manner and destroyed the crystallization of the $\mathrm{W}_{18} \mathrm{O}_{49}$ thin film at high crystallization temperatures. ${ }^{(17)}$

As a result, the XRD spectrum peak of $\mathrm{W}_{18} \mathrm{O}_{49}(010)$ located at $2 \theta=23.54^{\circ}$ suggests that we can achieve the highest intensity of the $\mathrm{W}_{18} \mathrm{O}_{49}$ (010) XRD peak by controlling the annealing temperature at $600{ }^{\circ} \mathrm{C}$. Moreover, the full width at half maximum (FWHM) of the $\mathrm{W}_{18} \mathrm{O}_{49}(010)$ XRD peak located at $2 \theta=23.54^{\circ}$ was only $0.31^{\circ}$ for the $600{ }^{\circ} \mathrm{C}$-annealed $\mathrm{W}_{18} \mathrm{O}_{49}$ film. Such a narrow linewidth implies that the $600{ }^{\circ} \mathrm{C}$-annealed $\mathrm{W}_{18} \mathrm{O}_{49}$ film shows the optimum crystallization condition.

\subsection{Analyses of optical and electrical properties}

Figure 3 shows the room-temperature PL spectra of the as-deposited and annealed $\mathrm{W}_{18} \mathrm{O}_{49}$ thin films shown in Fig. 1. In Fig. 3, two peaks at $410 \mathrm{~nm}(3.02 \mathrm{eV})$ and $464 \mathrm{~nm}(2.67 \mathrm{eV})$ were observed, which were referred to as the band-to-band emission and near-band-edge emission, respectively. It could be attributed to the recombination of free excitons ${ }^{(18)}$ and oxygen vacancies in the $\mathrm{W}_{18} \mathrm{O}_{49}$ lattice. ${ }^{(19)}$ Furthermore, the FWHMs of the near-band-edge emission of $\mathrm{W}_{18} \mathrm{O}_{49}$ thin- 


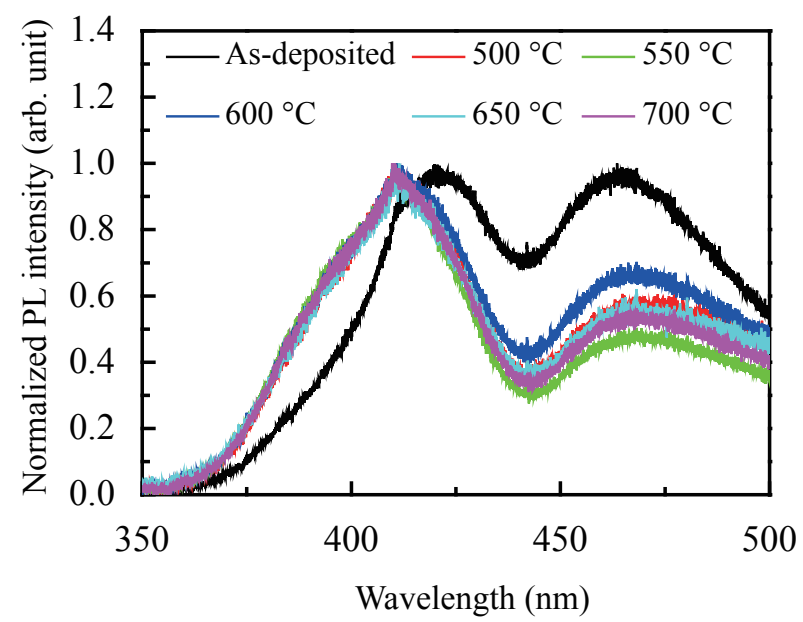

Fig. 3. (Color online) PL spectra of $\mathrm{W}_{18} \mathrm{O}_{49}$ thin films with different annealing temperatures.

film substrates annealed at $500,550,600,650$, and $700{ }^{\circ} \mathrm{C}$ were $33.3,34.5,33.4,33.6$, and $33.9 \mathrm{~nm}$, respectively. All of the spectra of the annealed $\mathrm{W}_{18} \mathrm{O}_{49}$ films were normalized to unity at $410 \mathrm{~nm}$. It was also found that the PL spectra of the annealed $\mathrm{W}_{18} \mathrm{O}_{49}$ films shifted to shorter wavelength, as reported by Sun et al. ${ }^{(20)}$ Such blue-shift effect could be explained in terms of recombination. On the other hand, the as-deposited film may possess many defects, which result in more excitons recombining in the way of the near-band-edge emission.

Figure 4 shows the $I-V$ characteristics of the PDs fabricated using $\mathrm{W}_{18} \mathrm{O}_{49}$ films measured in the dark (dark current) and under illumination (photocurrent). It can be seen that the measured current increased linearly with the applied bias. Such a result indicates that ohmic contacts were well formed between the Au electrodes and the underlying $\mathrm{W}_{18} \mathrm{O}_{49}$ thin films. Here, we defined the $\mathrm{PD}$ with as-deposited films as $\mathrm{PD}$ as, with annealing at $500{ }^{\circ} \mathrm{C}$ as $\mathrm{PD}$-500, with annealing at 550 ${ }^{\circ} \mathrm{C}$ as PD_550, with annealing at $600{ }^{\circ} \mathrm{C}$ as PD_600, with annealing at $650{ }^{\circ} \mathrm{C}$ as PD_650, and with annealing at $700{ }^{\circ} \mathrm{C}$ as $\mathrm{PD} \_700$ for the fabrication of $\mathrm{W}_{18} \mathrm{O}_{49}$ PDs.

It was found in Fig. 4(a) that the dark current of the $\mathrm{W}_{18} \mathrm{O}_{49}$ PDs used in this study decreased significantly as the annealing temperature was increased to $600{ }^{\circ} \mathrm{C}$. This result suggests that increasing the annealing temperature to over $600{ }^{\circ} \mathrm{C}$ will restrain the oxygen vacancies and thus decrease the dark current. Moreover, with $5 \mathrm{~V}$ applied bias, the dark currents of PD_as, PD_500, PD_550, PD_600, PD_650, and PD_700 are $2.7 \times 10^{-8}, 2.7 \times 10^{-8}, 8.9 \times 10^{-9}, 2.6 \times 10^{-10}, 4.3$ $\times 10^{-10}$, and $1.1 \times 10^{-10} \mathrm{~A}$, respectively. The small dark current of the annealed PDs could be attributed to the reduced oxygen vacancies. Figure 4(b) shows the photocurrents measured under illumination; it can be seen clearly that the photocurrents increased linearly with increasing applied bias. Again, the linear behavior reveals that good ohmic contacts were formed between the $\mathrm{Au}$ electrodes and the underlying $\mathrm{W}_{18} \mathrm{O}_{49}$ thin films. In addition, the best performance of $\mathrm{W}_{18} \mathrm{O}_{49}$-based PD was PD_600, which was obtained by annealing $\mathrm{W}_{18} \mathrm{O}_{49}$ thin films at $600{ }^{\circ} \mathrm{C}$. This result is in a good agreement with the XRD spectrum experiment result, which shows the highest intensity of the $\mathrm{W}_{18} \mathrm{O}_{49}(010) \mathrm{XRD}$ peak located at $2 \theta=23.54^{\circ}$ by controlling the annealing temperature at $600{ }^{\circ} \mathrm{C}$. Furthermore, the photocurrent at $410 \mathrm{~nm}$ and the dark current measured at $5 \mathrm{~V}$ bias are $1.7 \times 10^{-7}$ and $2.6 \times 10^{-10} \mathrm{~A}$, respectively. As a result, the photo-to-dark current contrast ratio is $6.5 \times 10^{2}$, and the responsivity at $410 \mathrm{~nm}$ for PD_600 is $0.0268 \mathrm{~A} / \mathrm{W}$. 


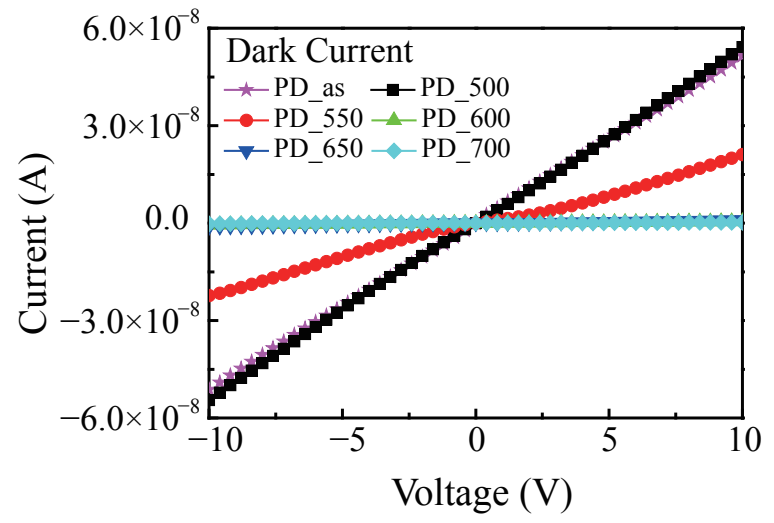

(a)

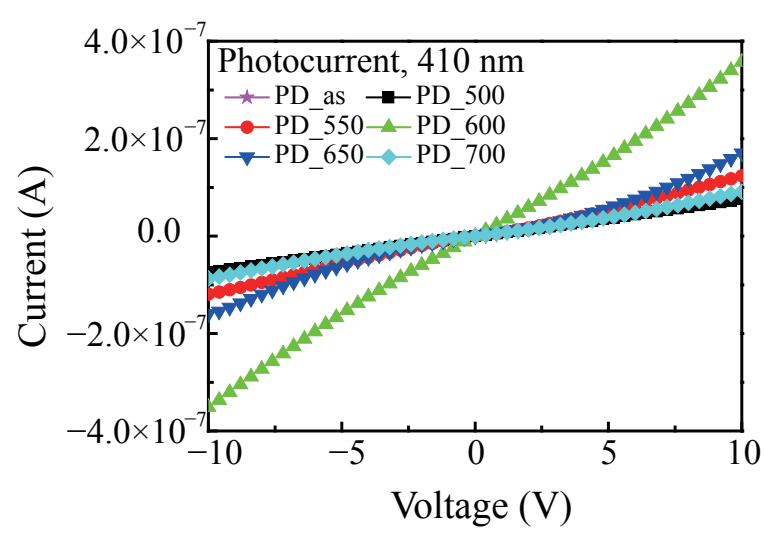

(b)

Fig. 4. (Color online) $I-V$ characteristics of $\mathrm{W}_{18} \mathrm{O}_{49} \mathrm{PD}$ measured in (a) dark state and (b) illumination state.

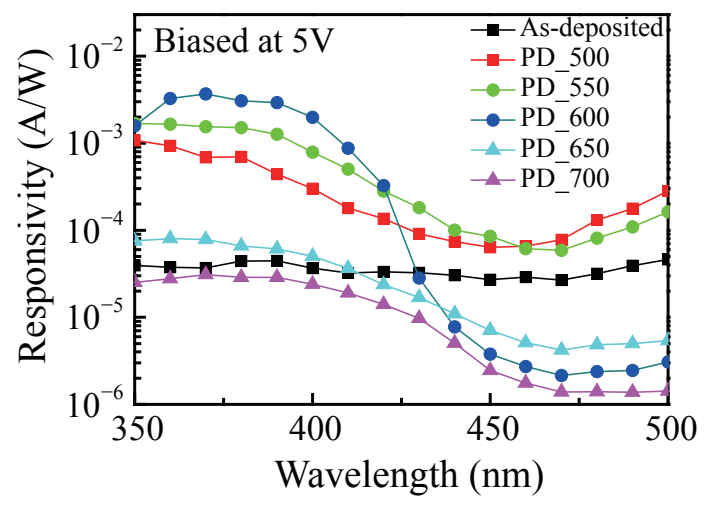

Fig. 5. (Color online) Spectral responses of annealed $\mathrm{W}_{18} \mathrm{O}_{49}$ PDs.

Figure 5 shows the measured spectral response of the $\mathrm{W}_{18} \mathrm{O}_{49}$ thin-film PDs biased at $5 \mathrm{~V}$ at room temperature. The responsivities at $410 \mathrm{~nm}$ for PD_500, PD_550, PD_600, PD_650, and PD_700 were $1.8 \times 10^{-4}, 5.04 \times 10^{-4}, 8.74 \times 10^{-4}, 3.65 \times 10^{-5}$, and $1.91 \times 10^{-5} \mathrm{~A} / \mathrm{W}$, respectively. Also, the photoresponsivities were nearly constant in the UV region of 360-390 nm, suggesting that the $\mathrm{W}_{18} \mathrm{O}_{49}$-based $\mathrm{PD}$ is potentially useful in the UV spectral region.

\section{Discussion}

Here, we defined the UV-to-visible rejection ratio as the responsivity measured at $410 \mathrm{~nm}$ divided by the responsivity measured at $470 \mathrm{~nm}$. On the basis of this definition, the rejection ratios of PD_500, PD_550, PD_600, PD_650, and PD_700 corresponded to 2.31, 8.57, 407.8, 8.70, and 13.75 , respectively. It can be seen clearly that the largest rejection ratio is 407.8 for PD_600 when a bias of $5 \mathrm{~V}$ is applied. The large rejection ratio could be attributed to its small dark current and transformation from crystal type to optical-sensitive structure at $600{ }^{\circ} \mathrm{C}$ annealing treatment. This 
may be due to the fact that the crystallization of the $\mathrm{W}_{18} \mathrm{O}_{49}$ thin films reached a temperature critical point and led to morphological evolution. ${ }^{(15)}$ In addition, we found that the response and recovery time of tungsten oxide PDs are strongly dependent on the atmospheric environment. On the basis of this phenomenon, the details of the response and recovery time in changing gas environments, even high-humidity environments, ${ }^{(21)}$ and the surface effects on electron transport due to the atmosphere will be investigated experimentally in the future.

\section{Conclusions}

We reported on a $\mathrm{W}_{18} \mathrm{O}_{49}$ film that was fabricated by the sol-gel method to observe the performance of $\mathrm{W}_{18} \mathrm{O}_{49}$-based MSM PDs. The photodetection study consisted of two major parts. First, owing to the fabrication of a $\mathrm{W}_{18} \mathrm{O}_{49}$ film with the best performance, we determined the optimum annealing temperature. Second, owing to the best responsivity performance obtained, we examined the temperature dependence of characteristics in MSM PDs. It was found that $\mathrm{W}_{18} \mathrm{O}_{49}$ thin films annealed at $600{ }^{\circ} \mathrm{C}$ have a very compact structure and are well crystallized. The grain size is approximately $60-70 \mathrm{~nm}$. The FWHM of the $\mathrm{W}_{18} \mathrm{O}_{49}(010)$ XRD peak located at $2 \theta=23.54^{\circ}$ was only $0.31^{\circ}$ for the $600{ }^{\circ} \mathrm{C}$-annealed $\mathrm{W}_{18} \mathrm{O}_{49}$ film. The responsivity at $410 \mathrm{~nm}$ and the rejection ratio for PD_600 were $0.0268 \mathrm{~A} / \mathrm{W}$ and 407.8 , respectively. A photo-to-dark current contrast ratio of $6.5 \times 10^{2}$ was achieved. $I-V$ measurement also indicated that the optimum annealing temperature for the substrates was $600^{\circ} \mathrm{C}$.

\section{Acknowledgements}

This work was supported by the Ministry of Science and Technology under grant No. MOST104-2221-E-158-003, and Shih Chien University, Kaohsiung Campus under contract No. USC104-05-05008. The authors also thank Prof. Huang of National Taiwan University of Science and Technology for equipment support.

\section{References}

1 V. Parisa and S. S. Khatiboleslam: J. Nano Res. 33 (2015) 1126.

2 C. Y. Zhao, X. H. Wang, J. Y. Zhang, Z. G. Ju, C. X. Shan, B. Yao, D. X. Zhao, D. Z. Shen, and X. W. Fan: Thin Solid Films 519 (2011) 1976.

3 O. Bohnke, M. Rezrazi, B. Vuillemin, C. Bohnke, P. A. Gillet, and C. Rousselot: Sol. Energy Mater. Sol. Cells 25 (1992) 361.

4 A. Dipaola, F. Diquarto, and C. Sunseri: J. Electrochem. Soc. 125 (1978) 1344.

5 R. Hurdich: Electron. Lett. 11 (1975) 142.

6 P. Judeinstein and J. Livage: J. Mater. Chem. 1 (1991) 621.

7 O. Lev, Z. Wu, S. Bharathi, V. Glezer, A. Modestov, J. Gun, L. Rabinovich, and S. Sampath: Chem. Mater. 9 (1997) 2354.

8 B. W. Faughnan, R. S. Crandall, and P. M. Heyman: RCA Rev. 36 (1975) 177.

9 A. Rougier, F. Portemer, A. A Quédé, and M. El Marssi: Appl. Surf. Sci. 153 (1999) 1.

10 M. Zayat, R. Reisfeld, and H. Minti: J. Sol-Gel Sci. Technol. 11 (1998) 161.

11 B. Orel, N. Groselj, U. Opara Krasovec, M. Gaberscek, P. Bukovec, and R. Reisfeld: Sens. Actuators, B 50 (1998) 234.

12 Q. H. Li, T. Gao, Y. G. Wang, and T. H. Wang: Appl. Phys. Lett. 86 (2005) 110.

13 O. Harnack, C. Pacholski, H. Weller, A. Yasuda, and J. M. Wessels: Nano Lett. 3 (2003) 305.

14 Y. W. Heo, B. S. Kang, L. C. Tien, D. P. Norton, F. Ren, J. R. La Roche, and S. J. Pearton: Appl. Phys. A 80 (2005) 502. 
15 B. R. Huang, S. C. Hung, C. Y. Lin, and Y. J. Chen: J. Mater. Sci.: Mater. Electron. 25 (2014) 408.

16 J. H. Ha, P. Muralidharan, and D. K. Kim: J. Alloys Compd. 475 (2009) 446.

17 K. J. Chen, F. Y. Hung, S. J. Chang, and S. J. Young: Mater. Trans. 50 (2009) 922.

18 W. D. Yu, X. M. Li, and X. D. Gao: Appl. Phys. Lett. 84 (2004) 2658.

19 Y. C. Liu, Y. W. Chen, C. L. Shao, and S. X. Lu: J. Sol-Gel Sci. Technol. 39 (2006) 57.

20 S. Sun, X. Chang, and Z. Li: Mater. Res. Bull. 45 (2010) 1075.

21 I. Toshio, M. Ichiro, and T. Jun: Sens. Mater. 24 (2012) 1319. 